\title{
Decreased visual acuity in benign annular macular dystrophy
}

\section{Disminución de la agudeza visual en distrofia macular anular benigna}

\author{
René Hernán Parada-Vásquez* \\ Anterior Segment Department, Instituto de la Visión, Nuevo León, México
}

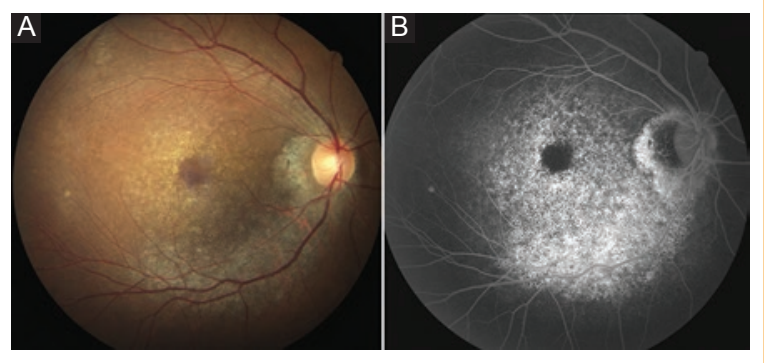

Figure 1. A: color photograph of the fundus of the right eye, showing color changes of the retinal pigment epithelium at the perimacular level. B: Fluorescein angiography, at mid arteriovenous phase, evidencing areas of atrophy in the perimacular pigment epithelium, with extensive window defects in the inferior temporal arcade.

A 32-year-old female patient, with decreased visual acuity in both eyes. At examination: visual acuity, far vision without correction of the right eye: $20 / 80$ and of left eye: 20/60. Fundoscopy in both eyes showed: well-defined optic disk, color changes of the perimacular pigment epithelium, as well as in the temporal arcades, more evident in the inferior region (Fig. 1A).

In fluorescein angiography: areas of atrophy of the perimacular pigment epithelium are evidenced, with an abnormal distribution, presenting window defects that coincide with abnormal distribution of lipofuscin by autofluorescence (Fig. 1B).

\section{Ethical disclosures}

Protection of human and animal subjects. The authors declare that no experiments were performed on humans or animals for this study.

Confidentiality of data. The authors declare that they have followed the protocols of their work center on the publication of patient data.

Right to privacy and informed consent. The authors have obtained the written informed consent of the patients or subjects mentioned in the article. The corresponding author is in possession of this document.

\section{Funding}

The author received no funding for this work.

\section{Conflict of interest}

The author declares no conflict of interest.

\section{Correspondence:}

*René Hernán Parada-Vásquez

E-mail: rene_hernan@ hotmail.com
Available online: 07-05-2018

\section{Rev Mex Oftalmol (Eng). 2018;92(2):94} www.rmo.com.mx

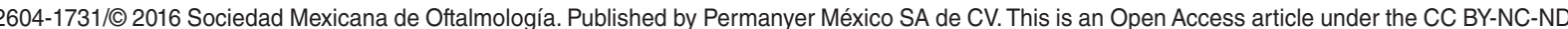
license (http://creativecommons.org/licenses/by-nc-nd/4.0/). 